\title{
DESIGN AND ANALYSIS OF COCONUT EMBRYO CULTURE EXPERIMENTS
}

\author{
By \\ Anitha Karun; K. Muralidharan; K. K. Sajini and V.A. Parthasarathy ${ }^{1}$
}

\begin{abstract}
The experimental design and data analysis procedures followed for standardizing the CPCRI protocol of coconut zygotic embryo culture are described. The availability of human resources (for initiating the cultures as well as periodic sub-culturing), laboratory space for maintaining culture, infrastructure for preparation of adequate culture media etc, are the important factors to be considered at the planning stage. Since the response of interest per experimental unit is discrete (germinated or not), it is desired to have a "plot size" of 20. Based on the experimental errors obtained for various treatments, attempts were made to obtain the replication size for a specified value of treatment difference to be tested. In most of the experiments, per cent germination was not following the assumption of ANOVA, even after transformation. In such situation, the chi-square test was employed to study the influence of treatments on germination. The coefficient of variation in most of the experiments was below $20 \%$.
\end{abstract}

${ }^{1}$ Central Plantation Crops Research Institute (CPCRI), Kasaragod, India. 


\section{INTRODUCTION}

The importance of planning experiments and statistical analysis of experimental data needs no emphasize. Discussion on this aspect among subject matter specialists will improve the experimentation techniques in the respective fields. Following the standardization of embryo culture techniques in coconut, embryos are used as the experimental material for many research studies. The summary statistics from the concluded experiments will be of much use in planning new experiments. Keeping this in view, a retrospective analysis of experiments conducted for standardization of the 'CPCRI protocol of coconut embryo culture' (Anitha Karun et al., 1999; Anitha Karun, 2001) was attempted in this paper. Various factors considered while planning the experiments and alternative methods of analysis were also discussed.

\section{MATERIALS AND METHODS}

The zygotic embryos of coconut form the experimental material. In the first phase experiments, embryos of West Coast Tall were used for reasons of abundance of material. Later, embryos of other cultivars were also tried. The availability of human resources (for initiating the cultures as well as periodic sub-culturing), laboratory space for maintaining cultures, infrastructure for preparation of adequate culture media etc. were considered while deciding the size of the experiment. Since the response of interest per experimental unit is binary (germinated or not), it was decided to group several units to form a replication of a treatment. In the initial phase, more number of embryos was used to constitute such groups but on standardization of procedures, the number is reduced. For reasons of contamination of cultures, each embryo was kept separately in tubes and bundled together to form groups. Labels were provided for each culture for identification. Randomization of treatments were followed as far as possible and on execution of one complete set of treatments, the same was repeated, which is analogous to blocking in field experiments. It took two to four days for the completion of a single replication in certain experiments. The advantages of 'blocking' of this kind include easiness for organizing the experiment, planning for periodic sub-culturing and reducing the chances of complete contamination of cultures of any particular treatment. The data was analyzed following procedures of randomized complete block design. Table 1 summarizes the details of various experiments conducted for standardizing the CPCRI protocol of coconut zygotic embryo culture.

Standard procedures of statistical analysis were followed for analyzing the data using subroutines developed at CPCRI. However, for an explorative investigation of the data, procedures available with Statistical Package for Social Science (SPSS) were employed (SPSS, 1999). Data exploring techniques such as box-andwhisker display of data was used for checking the assumptions of equal 
variances and normality. On arranging the data in ascending or descending order, the 'box' is to have $50 \%$ data of the middle order; its length is referred as 'hspread'. The horizontal line inside the box marks the median. The display is also to show the presence of outliers (data that are outside the hinges (top as well as bottom) for more than one and half to three time the hspread) and extreme values (more than three time the hspread). Besides this, the explore option of descriptive statistics under analysis menu of SPSS offers few other tools for verifying the assumptions.

Angular transformation is attempted wherever necessary using the SPSS syntax arsin (sqrt (proportion). Besides performing the F-test, the unvaried analysis of variance procedure offers test of contrasts. The between-treatments sums of squares may be partitioned to various types of contrasts such as simple deviation (compares each treatment with grand mean), simple (with last or first treatments), Helmert (each treatment with mean of subsequent treatments), repeated (each treatment with subsequent treatment) for easy interpretation of results.

When both the assumptions of ANOVA are violated (i.e. normality as well as equality of variances), no transformation works satisfactorily. An alternative is then to employ rank transformation as suggested by Conomver (1980) and proceed with the conventional analysis of variance test. The Friedman's non-parametric test may also be employed for which the data has to be re-arranged such that the treatments form the variables (columns) and cases (rows) to represent replications. The chi-square test may also be considered to test the 'independence' between treatments and response (germinated or not germinated). With frequencies as cell values, the command Weight as (under Data menu) has to be executed for the frequency-variable prior to execute Crosstabs under the Analysis menu for performing the chi-square test. Various graphical displays of the data were used for deciding the procedure of analysis and also for interpretation of results.

\section{RESULTS AND DISCUSSION}

As stated earlier, the response of prime importance in experiments conducted for standardization of the protocol was per cent germination. In some experiments, a small fraction of cultures were contaminated and were excluded while working out the per cent germination (provided the contamination is not specific to one or other treatment). Growth of embryos (gain in weight), in vitro growth of seedlings (length of shoot/root, volume of root, number of leaflets etc) and mortality during ex vitro establishment of seedlings are other important characters but not discussed in this paper.

As expected, in most of the experiments, the variable 'proportion of germination' was not following the assumption of normality. The equalvariance assumption is also seldom satisfied. For illustration, consider the first experiment. The per cent germination of 8-month old embryos was $54 \%$ much below to $72 \%$ germination of 11-month old embryos. 
But still the F-test was not significant. Could it be due to very small error degrees of freedom? Whether the assumptions of the test are violated? If so, whether transformation of data will be of any help?

It is obvious from Figure 1 that per cent germination in Experiment 1 does not satisfy the assumptions of ANOVA. There is also no indication of outliers in the data. The angular transformation as well as rank transformation did not alter the conclusions. The Friedman's nonparametric test too was employed but not significant.

Having realized that the replication size is a limitation in this experiment to try the conventional procedures, we changed our attention to chi-square test. The hypothesis that the germination is independent of agecategories was rejected with regard to the 8- and 11-month old embryos (computed chi-square value is 4.471; significant at 5\%). To conclude, the experiment did reveal the possibility of retrieving immature embryos but at less proportion compared to 11-month old embryos.

Experiments 2 to 5 were single replicated trials: It was evident from the data that embryos can easily be stored for 2 months without affecting the viability. However, the germination was very less when stored for 6 months. The survival of immature embryos even up to 2 months' storage was seemed to be difficult. Chi-square test was employed to test the independence of stored in sterile water or not vs. germinated or not: With regard to 2 and 4 months' storage, the test was not significant implying the feasibility of short term storage of embryos.

The appropriateness of Y3 solid medium for retrieving 11-month old embryos was revealed in Experiment 6 but no medium was found to be satisfactory to improve the recovery of immature (8-month old) embryos (Experiment 7). The germination of dwarf embryos in different treatment combinations tried in experiment 8 was on par.

In Experiment 9, treatment effects were found to be significant after angular transformation. Contrast analysis was employed to identify the treatments that are significantly better than the control (Table 2). The 'repeated' contrast analysis revealed that no significant difference between the levels of any of the antioxidants tried. With regard to agar as gelling agent (Experiment 10), treatment effects were not significantly different. Main effect phytagel was superior to agar in Experiment 11.

The ANOVA (even after transformation) failed to detect any difference among treatments in Experiment 12. In this experiment too the assumptions of ANOVA were not found hold good. The graphical display of percent germination (Fig.2) suggests differential pattern of germination among treatments in mature and immature embryos. Therefore chi-square test was employed separately for mature and immature embryos. Results showed that the chi-square test is significant with regard to germination of mature embryos.

In experiment 13 too the ANOVA test failed to detect treatment 
effects. Again when ANOVA was performed separately for the mature embryos, the test was significant for $(\mathrm{F}=6.3$ for $\mathrm{df}(3,5)$ To test the interaction between ABA levels and age of embryos, two-way contingency tables were formed for every level of ABA. Significant chi-square was obtained for the last level suggesting, differential germination for mature and immature embryos at that level. The graphical representation of data is in support of this finding (Fig. 3)

The coefficient of variation in most of the experiments was not very high (Table 1) except for the Experiment 7. Angular transformation of data helped to reduce the $\mathrm{CV}$ in other experiments. The effect of plot size on variance with regard to different percent germination is shown in Fig 4. Plot size below 20 may result in large variance when germination per cent is either too high or low (a known result of binomial distribution).

It was observed that the experimental error varied between 0.006 and 0.057 . Number of replications required for pre-specified treatment differences for different values of experimental error were worked out and plotted in Fig. 5. When experimental error is expected to be low, replication size of 3 is quite adequate even to detect treatment differences of $10 \%$. On compromising the per cent difference to be detected to $20 \%$, the size of replication reduced to below 5 despite large experimental errors.

\section{CONCLUSIONS}

Planning of experiments and statistical analysis of data played an important role for evolving the CPCRI protocol of coconut zygotic embryo culture. It was observed from many experiments that the assumptions of ANOVA were violated with regard to the response variable (per cent germination etc.). Non-parametric methods including the chi-square test may be attempted in such cases. Experiments in which the response of importance is binary, the 'plot size' of 20 will reduce the problem due to unequal variances. Statistical application software that integrating different procedures as well as graphical representation of data will be of much helpful for drawing valid conclusion.

\section{REFERENCES}

Karun, A., Sajini, K. K. and Shivashankar, S. 1999. Embryo culture of coconut CPCRI protocol. Indian J. Hort. 56(4):348-353.

Karun, A. 2001. Embryo culture protocol for collection and exchange of coconut germplasm. Indian Coconut J.31(9):17-18.

Conover 1980. Practical Non Parametric Statistics. John Wiley and Sons Inc. Canada.

SPSS 1999. SPSS (v. 10.0). Manuals. SPSS Inc., Chicago. 
Table 1. Index of experiments conducted for evolving the CPCRI protocol of coconut zygotic embryo culture technique

\begin{tabular}{|c|c|c|c|c|}
\hline Sl. No. & Treatments & $\begin{array}{l}\text { Replica- } \\
\text { tions }\end{array}$ & Plot size & $C V(\%) *$ \\
\hline 1 & 8-, 9- and 11- month old embryos & 3 & 20 & $18.9 ; 13.8$ \\
\hline 2 & $\begin{array}{l}3 \times 2 \text { factorial experiment } \\
\text { Storing medium: } \mathrm{Y}_{3}+\text { sugar; } \mathrm{Y}_{3}+\text { charcoal; Sterile water } \\
\text { Period of storage: } 2 \text { and } 6 \text { months } \\
\text { Control: Retrieval Medium (without any storage) - Mature } \\
\quad \text { embryos }\end{array}$ & 1 & 15 & \\
\hline 3 & $\begin{array}{l}\text { Three storing media and control as in Experiment } 2 \text { (immature } \\
\text { embryos) }\end{array}$ & 1 & 15 & \\
\hline 4 & $\begin{array}{l}\text { Three periods of storage : } 2,4 \text { and } 6 \text { months mature embryos } \\
\text { in sterile water }\end{array}$ & 1 & 50 & \\
\hline 5 & $\begin{array}{l}\text { Two periods of storage : } 2 \text { and } 4 \text { months - mature embryos in } \\
\text { sterile coconut water }\end{array}$ & 1 & 30 & \\
\hline 6 & $\begin{array}{l}2 \times 2 \text { Factorial experiment: } \\
\text { Basal medium }: \mathrm{Y}_{3} \text { and } \mathrm{MS} \\
\text { State of the medium : Solid and Liquid }\end{array}$ & 3 & 20 & $22.1 ; 21.3$ \\
\hline 7 & $\begin{array}{l}4 \times 2 \text { Factorial experiment: } \\
\text { Basal medium : } \mathrm{EC}_{2}, \mathrm{ECG}_{2}, \mathrm{ECM}_{2} \text { and } \mathrm{AYH} \\
\text { State of the medium : Solid and Liquid }\end{array}$ & 8 & 5 & $65.9 ; 78.0$ \\
\hline 8 & $\begin{array}{l}3 \mathrm{x} 4 \text { factorial experiment } \\
\text { Basal medium : } 1 / 2 \mathrm{Y}_{3}, \mathrm{Y}_{3} \text { and } 1 / 2 \mathrm{MS} \\
\text { Sucrose \& Charcoal combinations: } \\
\quad 30 \& 2 \mathrm{~g} / \mathrm{l}, 40 \& 2 / 1,60 \& 2.5 \mathrm{~g} / \mathrm{l} \text { and } 30 \mathrm{~g} / \mathrm{l} \\
\quad \text { glucose }+30 \mathrm{~g} / \mathrm{l} \text { sucrose } \& 2.5 \mathrm{~g} / 1 \text { charcoal }\end{array}$ & 2 & 10 & 10.6 \\
\hline 9 & $\begin{array}{l}\text { Three sources at } 2 \text { levels each } \\
\text { Charcoal }(1,2 \mathrm{~g} / \mathrm{l}), \mathrm{DIECA}(100,150 \mathrm{mg}), \mathrm{PVP}(50,100 \mathrm{mg}) \\
\text { and control as the RM - the gelling agent was phytagel }\end{array}$ & 3 & 10 & $23.7 ; 18.0$ \\
\hline 10 & Same as in experiment 9 - agar as gelling agent & 3 & 10 & $10.5 ; 15.6$ \\
\hline 11 & Phytagel $(1,1.5$ and $2 \mathrm{~g} / \mathrm{l}) ;$ Agar $(4,4.5$ and $5 \mathrm{~g} / \mathrm{l})$ & 3 & 10 & 9.9 \\
\hline 12 & $\begin{array}{l}2 \times 4 \text { factorial experiment } \\
\text { Age of embryo : 9- and } 11 \text {-month old } \\
\mathrm{GA}_{3}: 1,0.5,0.1 \text { and } 0.05 \text { micro molar }\end{array}$ & 3 & 20 & $23.0 ; 18.5$ \\
\hline 13 & $\begin{array}{l}2 \times 4 \text { factorial experiment } \\
\text { Age of embryo : 9- and } 11 \text {-month old } \\
\text { ABA : } 0,10.20 \text { and } 30 \text { micro molar }\end{array}$ & 3 & 20 & $16.1 ; 13.6$ \\
\hline
\end{tabular}

* Wherever two values given, the second value correspond to angular transformed data 
Table 2. Contrast analysis for detecting significant effects

\begin{tabular}{|c|c|c|}
\hline Simple contrast (treatment vs. control) & $\begin{array}{c}\text { Contrast } \\
\text { Estimate }\end{array}$ & Significant level \\
\hline Charcoal (1) & -.476 & .006 \\
\hline Charcoal (2) & -.450 & .008 \\
\hline DiECA (1) & -.332 & .038 \\
\hline DiECA (2) & -.583 & .002 \\
\hline $\operatorname{PVP}(1)$ & -.469 & .007 \\
\hline $\operatorname{PVP}(2)$ & -.397 & .017 \\
\hline
\end{tabular}
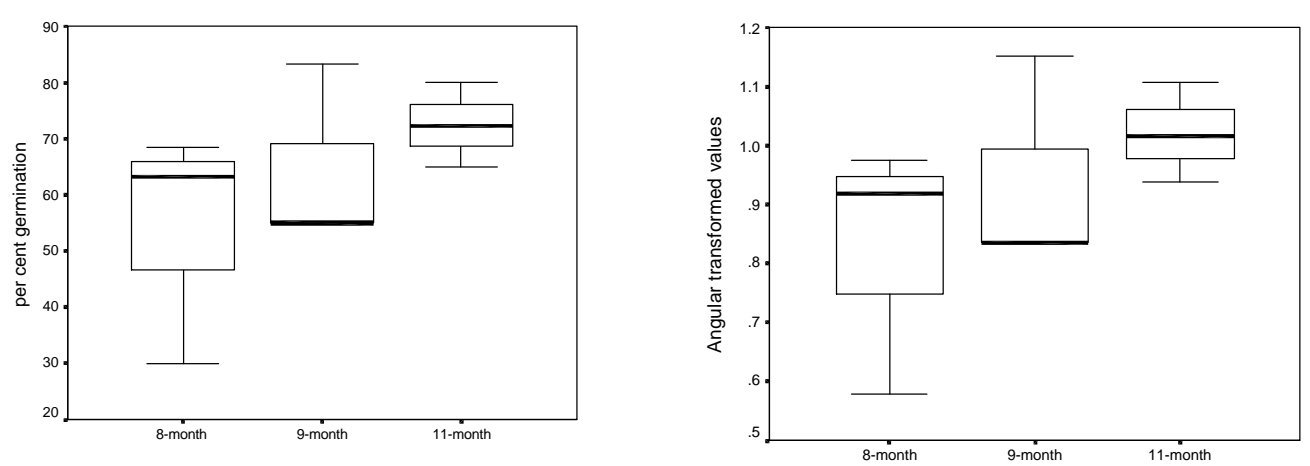

Fig. 1. The treatment wise box-and-whisker display of percent germination and values after angular transformation in Experiment 1. 


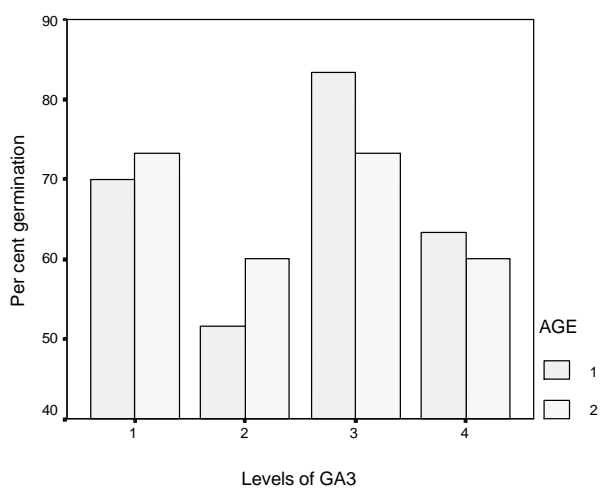

Fig. 2. Response to $\mathrm{GA}_{3}$ (levels 1 to 4 represents respectively 1 , $.5, .1$ and 0.05 micro molar); In figure, Age 1 is mature embryos and Age 2 is immature embryos

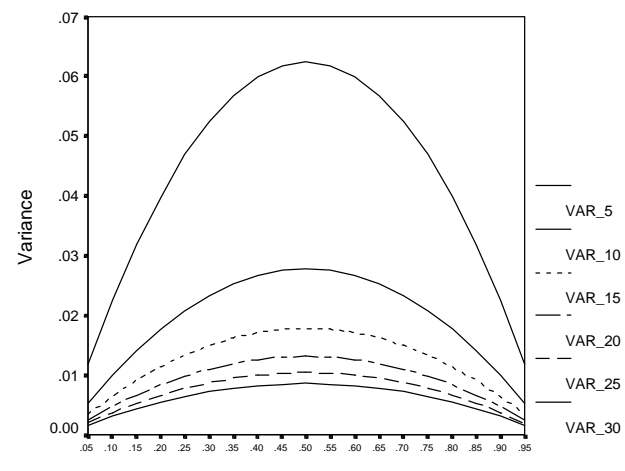

Value of proportion

Fig. 4. Variance is influenced by 'plot size'. In figure, var_5 etc. is to represent the line showing values of variance for different percentage germination for a 'plot size' of 5 etc.

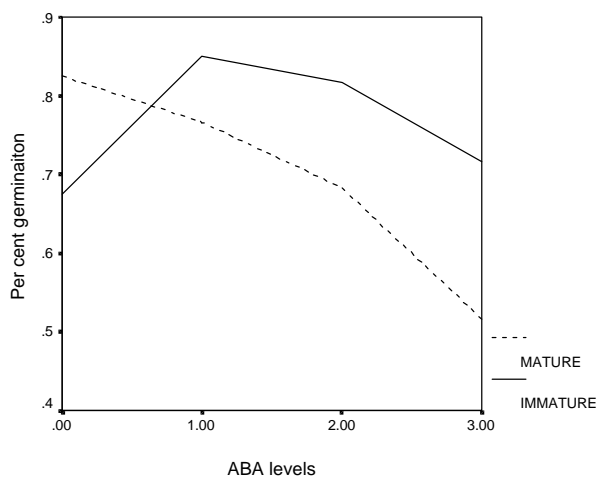

Fig. 3. Response to ABA (levels 0 to 3 represents respectively $0,10,20$, and 30 micro molar)

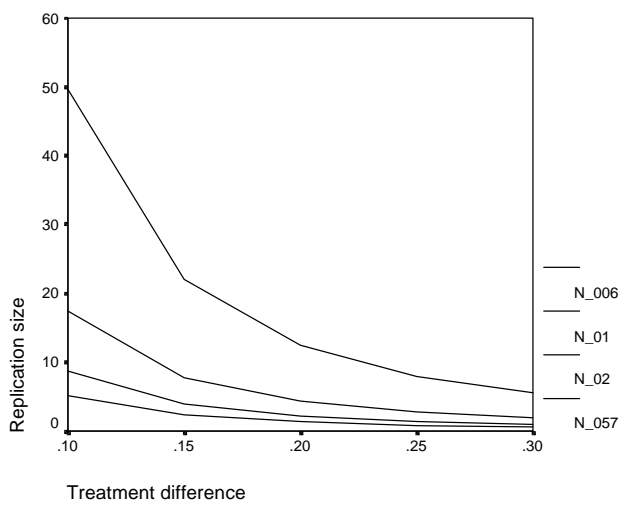

Fig. 5. Number of replications required for detecting specific treatment differences under varying experimental error. In figure N.006 etc. to indicate the line showing values of replication size for experimental error as 0.006 etc. 